\title{
Rectangular Microstrip Patch Antenna Using Air as Substrate for S-Band Communication
}

\author{
Manish Gupta ${ }^{1}$, Saurabh Sachdeva ${ }^{1}$, N. Kumar Swamy ${ }^{2}$, Inder Pal Singh ${ }^{3}$ \\ ${ }^{1}$ Department of EECE, ITM University, Gurgaon, India, ${ }^{2}$ Departmentof Electrical and Electronics Engineering, ITM University, Gur- \\ gaon \& Raipur, India, ${ }^{3}$ Departmentof Mechanical Engineering, Shinas College of Technology, Shinas, Oman. \\ Email:manish911989@gmail.com, saurabhsachdeva@itmindia.edu, nkumarswamy15@gmail.com, ipsinghphys@gmail.com
}

Received April 21 ${ }^{\text {st }}, 2013$; revised December 21 $1^{\text {st }}, 2013$; accepted January $10^{\text {th }}, 2014$

Copyright (C) 2014 Manish Gupta et al. This is an open access article distributed under the Creative Commons Attribution License, which permits unrestricted use, distribution, and reproduction in any medium, provided the original work is properly cited. In accordance of the Creative Commons Attribution License all Copyrights (c) 2014 are reserved for SCIRP and the owner of the intellectual property Manish Gupta et al. All Copyright (C) 2014 are guarded by law and by SCIRP as a guardian.

\section{ABSTRACT}

A Rectangular Microstrip Patch Antenna model is proposed using air as a substrate to study the characteristics of designed antenna. The dimensions of designed antenna are $17 \mathrm{~mm} \times 16.66 \mathrm{~mm}$ with substrate at frequency 3.525 GHz. In this paper, the simulation is performed by using software Computer Simulation Technology (CST) Microwave studio based on finite difference time domain technique. The characterization of the designed antenna was analyzed in terms of return loss, bandwidth, directivity, gain, radiation pattern, VSWR.

\section{KEYWORDS}

\section{Rectangular Microstrip Patch Antenna; Air Substrate; Directivity}

\section{Introduction}

Due to attractive and unique properties (e.g. low profile, conformal nature, and high speed), microstrip antennas are finding many applications in various fields like Microwave Engineering, Mobile Communication, Satellite Communication and aircraft systems. As a result, in recent years a considerable attention has been paid by many antenna designers to enhance the characteristics of these antennas. Microstrip patch antenna is special class of microstrip antennas. It consists of a patch on one side of a dielectric substrate and ground plane on the other side of the substrate [1]. The patch may be of any geometry like circular, triangular, rectangular, elliptical, square, and ring.

To meet the requirement of low profiling, conformal nature there are numerous materials used as a substrate like RT Duriod 5880, FR4, Alumina, Honeycomb, etc. [2].

Chandra et al. [3] proposed rectangular patch antenna using air as substrate for X-band. They used Agilent's E8363B network analyzer to obtain simulation results; from simulation results they observed 2 - $3 \mathrm{~dB}$ improvement in peak gain. Recently Ali et al. [4] designed the microstrip antenna using the same above substrate at 5.8
$\mathrm{GHz}$ frequency; results obtained by them strongly match with Chandra et al. [3].

In this paper a sincere attempt is made to design, model, optimize, and analysis rectangular microstrip patch antenna taking air as a substrate at $3.525 \mathrm{GHz}$ with the help of CST microwave [5] electromagnetic simulator.

\section{Antenna Design}

The selected dielectric materials for the antenna is air which has a dielectric constant of $1\left(\varepsilon_{r}\right)$ and the height of dielectric substrate is $1.5 \mathrm{~mm}(\mathrm{~h})$. We use CST microwave studio for design, modeling of proposed antenna. Microstrip feed line of 50 is used to feed the antenna.

The physical dimensions of the patch are based on the following formulae.

$$
\begin{gathered}
L=\frac{v_{0}}{2 f_{r \sqrt{\varepsilon_{r}}}} \\
W=\frac{v_{0}}{2 f_{r} \sqrt{\frac{2}{\left(\varepsilon_{r}+1\right)}}}
\end{gathered}
$$

where $L$ is the length, $W$ is the width and $f_{r}$ is fre- 
quency of the proposed antenna. $v_{0}$ is the space speed of light and $\varepsilon_{r}$ is relative permitivity of substrate. The physical dimensions of the ground plane are based on the following formulae.

$$
\begin{gathered}
L g=6 h+L \\
W g=6 h+W .
\end{gathered}
$$

where $\mathrm{Lg}$ and $\mathrm{Wg}$ are the length and width of the ground plane and $\mathrm{h}$ is the thickness of substrate. The geometry of proposed antenna is shown in Figure 1. The dimension is taken in millimeters (mm) and numbers of used mesh cells are 28,899.

\section{Optimized Antenna Design}

The dimensions of the metallic patch were slightly changed in order to improve the antenna performance parameters. A systematic study of thickness of the substrate is optimized from $0.2 \mathrm{~mm}$ to $4.4 \mathrm{~mm}$ in $0.1 \mathrm{~mm}$ increments. Finally the dimension of ground plane is $\mathrm{mm}$ and dimension of the patch is $17 \mathrm{~mm} \times 16.66 \mathrm{~mm}$.

\section{Simulation Results}

The measured and simulated results obtained for proposed antenna are presented graphically and numerically. CST microwave studio [5] electromagnetic simulator has been used to obtain these results.

\subsection{Return Loss}

Return Loss is a measurement from which we can judge how much amount of power is reflected back by the antenna.

The numerical value of the $S_{11}$ parameter from the Figure 2 is $-40.9638 \mathrm{~dB}$. There is one sharp narrow deep at $3.525 \mathrm{GHz}$ which shows that proposed antenna is a single band antenna. The bandwidth of the proposed antenna is found to be $140.6 \mathrm{MHz}$ from Figure 2.

\subsection{Radiation Pattern}

It is a graphical representation of the radiation properties of the antenna as a function of space coordinates [2]. Here the radiation pattern is determined in the far field region.

In this paper we only discuss two radiation properties namely directivity and polarization. Figures 3(a)-(d), are the $3 \mathrm{D}, 2 \mathrm{D}$, polar and Cartesian graphs of the radiation pattern respectively. Figure 3(a) shows that the directivity of the proposed antenna is $6.68 \mathrm{dBi}$, radiation efficiency is $-25.33 \%$ and total efficiency is $-25.33 \%$. It is also observed that maximum radiation is emitting from the center of the top the patch. This shows that the proposed antenna is feasible for S-band communication. From Figure3(c) an angular width (3dB) of antenna is $71.0 \mathrm{deg}$.

\subsection{VSWR}

VSWR is the way to see how much system is matched. It is the ratio between the maximum voltage and minimum voltage in the transmission line. For the best value of antenna it should be equal to 1 .

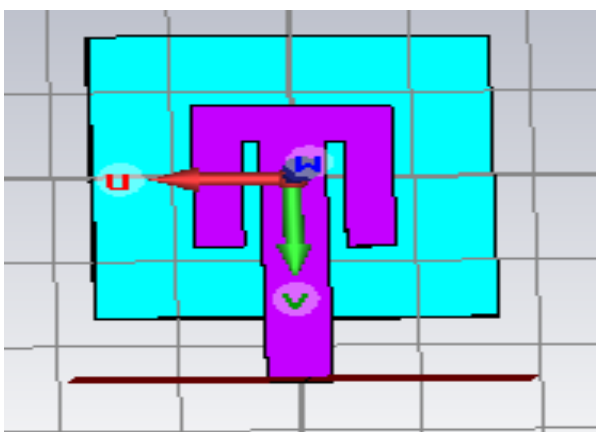

Figure 1. Geometry of proposed antenna operating at 3.525 GHz.

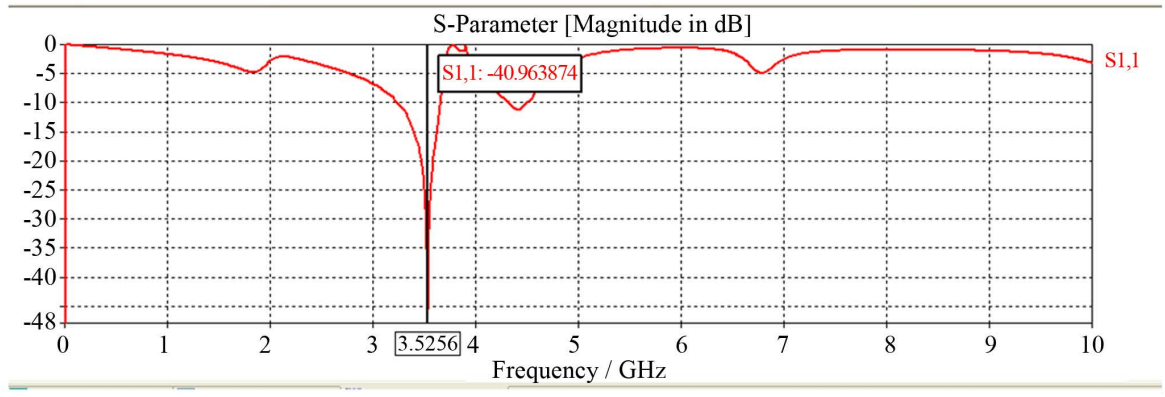

Figure 2. Return loss of purposed antenna at $3.525 \mathrm{GHz}$. 


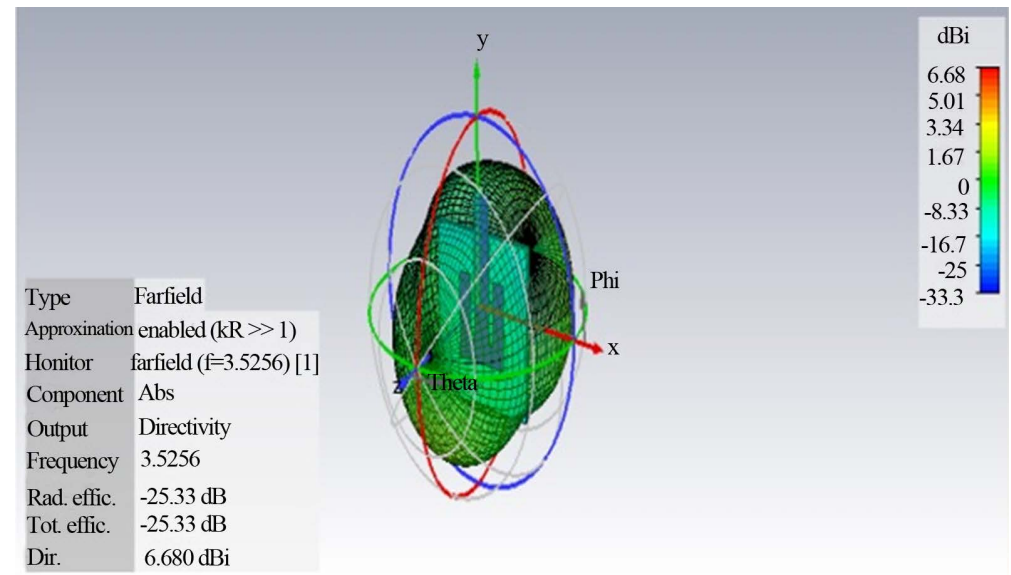

(a)

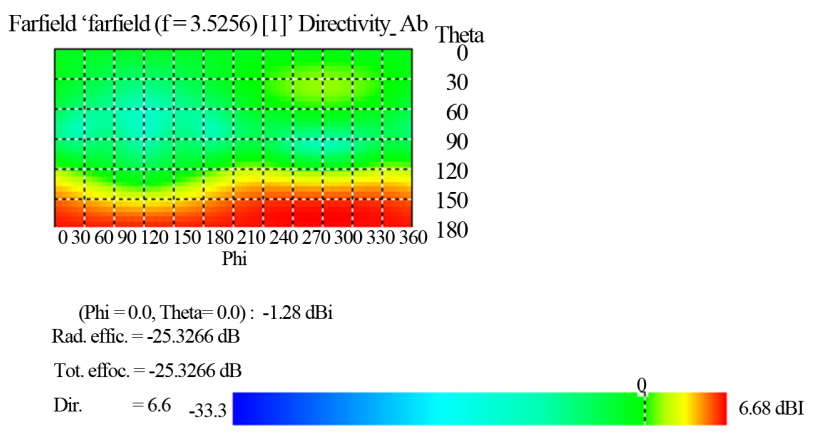

(b)

Farfield Directivity Abs (Phi=90)

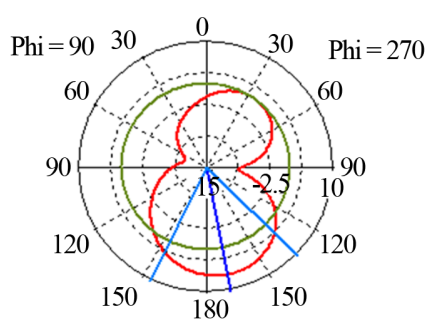

Theta / Degree vs. dBi
Frequency $=3.5256$

Main lobe magnitude $=6.7 \mathrm{dBi}$

Main lobe direction $=159.0 \mathrm{deg}$.

Angular width $(3 \mathrm{~dB})=71.0 \mathrm{deg}$.

Side lobe level $=-5.3 \mathrm{~dB}$

(c)

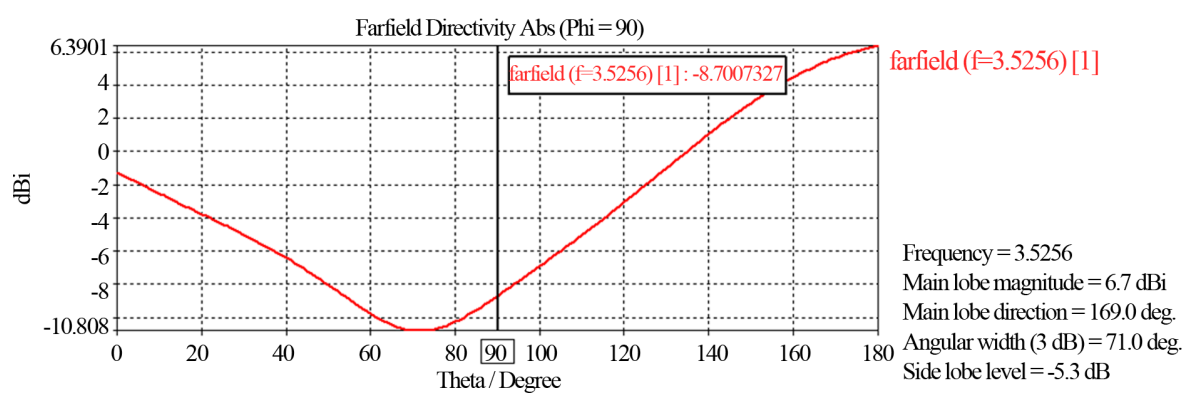

(d)

Figure 3. (a) 3D-Radiation pattern of proposed antenna at $3.525 \mathrm{GHz}$. (b) 2D-Radiation pattern of proposed antenna at 3.525 GHz. (c) Polar plot of proposed antenna operating at $3.525 \mathrm{GHz}$. (d) Cartesian plot of proposed antenna operating at 3.525 GHz . 


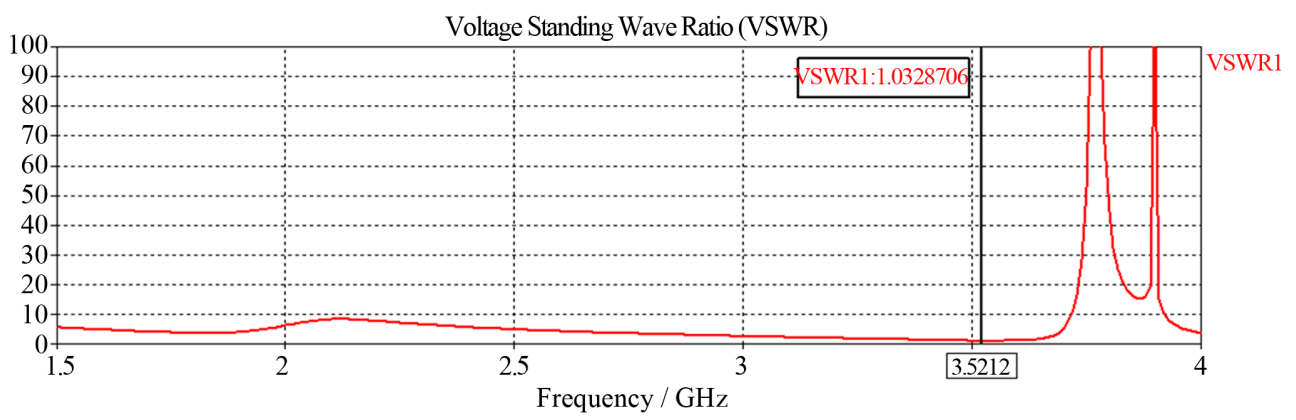

Figure 4. VSWR plot of proposed antenna operating at $3.52 \mathrm{GHz}$.

Looking at Figure 4, it can be observed that the measured value of VSWR is 1.0328 .

\section{Conclusion}

This paper has successfully designed a rectangular patch antenna operating at $3.525 \mathrm{GHz}$. It is found that using air as a substrate has been an improvement in return loss of $-40.965 \mathrm{~dB}$. The antenna also is capable of functioning at $3.525 \mathrm{GHz}$ with a gain of $6.68 \mathrm{dBi}$. This antenna has a big potential for a Microwave application.

\section{Acknowledgements}

Authors are thankful to reviewer for their helpful comments.

\section{REFERENCES}

[1] K. F. Lee and K. M. Luk, "Microstrip Patch Antennas,"
Imperial College Press, London, 2011.

[2] C. A. Balanis, "Antenna Theory," 2nd Edition, John Wiley \& Sons, Inc., 1997.

[3] C. Chandan, A Ghosh, S. K. Ghosh and S. Chattopadhyay, "Radiation Characteristics of Rectangular Patch Antenna Using Air Substrates," 2009 International Conference on Emerging Trends in Electronic and Photonic Devices \& Systems, Varanasi, 22-24 December 2009, pp. 346-348.

[4] M. T. Ali, "Gain Enhancement of Air Substrates at 5.8 GHz for Microstrip Antenna Array,” Microwave Technology Centre (MTC), Univ. Teknol. MARA (UiTM), Shah Alam, 2012, pp.477-480.

[5] CST Microwave Studio, "CSTGmbh-Computer Simulation Technology,” 2012. 